\section{Strain Ratio of Ultrasound} Elastography for the

\section{Evaluation of Tendon}

\section{Elasticity}

Ke-Vin Chang, $M D, P h D^{1,2}$, Wei-Ting $W u, M D^{2}$, Ing-Jeng Chen, $\mathrm{MD}^{1}$, Che-Yu Lin, $\mathrm{PhD}^{3}$

${ }^{1}$ Department of Physical Medicine and Rehabilitation, National Taiwan University Hospital and National Taiwan University College of Medicine, Taipei, Taiwan; 'Department of Physical Medicine and Rehabilitation, National Taiwan University Hospital, Bei-Hu Branch, Taipei, Taiwan; ${ }^{3}$ Institute of Applied Mechanics, College of Engineering, National Taiwan University, Taipei, Taiwan

Keywords: Tendon; Elastography; Ultrasound; Sonography

\section{Dear Editor,}

We have taken a considerable degree of interest in a recently published study by Yun et al. (1) regarding ultrasound elastography in the evaluation of the elasticity of rotator cuff tendons in patients with adhesive capsulitis (ACS). We would like to congratulate their fantastic work in exploring the potential utility of ultrasound elastography in quantitative assessment of shoulders with ACS. Their results demonstrated an increase in stiffness of the supraspinatus and infraspinatus tendons in shoulders with ACS, which were evident through both strain and shear wave elastography imaging. Here, we would like to humbly raise a query regarding their findings, specifically for the results

Received October 5, 2019; accepted after revision November 3, 2019.

Corresponding author: Ke-Vin Chang, MD, PhD, Department of Physical Medicine and Rehabilitation, National Taiwan University Hospital and National Taiwan University College of Medicine, No.7, Zhongshan South Road, Zhongzheng District, Taipei City 100, Taiwan.

- Tel: (886) 23717101 - Fax: (886) 23758363

- E-mail: kvchang011@gmail.com

This is an Open Access article distributed under the terms of the Creative Commons Attribution Non-Commercial License (https://creativecommons.org/licenses/by-nc/4.0) which permits unrestricted non-commercial use, distribution, and reproduction in any medium, provided the original work is properly cited. of strain elastography.

In their paper, the strain ratios of all the observed tendons were $<1$. For example, the median of the strain ratio of the supraspinatus tendon in the control group was 0.38 (Table 1 in the commented article) (1). The formula of the strain ratio used in this study was "subcutaneous fat tissue strain/target tendon strain." Since tissue strain is positively associated with the compressibility of the target (2), a harder structure characteristically has a smaller strain value. The tendon is theoretically harder than subcutaneous fat in normal individuals, which suggests that the tissue strain of the subcutaneous fat should be greater than that of the rotator cuff tendons. Therefore, the strain ratio observed in the subcutaneous fat strain divided by target tendon strain should be greater than 1 .

Furthermore, if the strain ratio is computed from the formula given by Yun et al. (1), it should be positively correlated with shear wave velocity and $\mathrm{kPa}$ values considering the fact that they are measurements of similar objects. The abovementioned statement has been confirmed by an in vitro study that examined the strain ratios in phantoms demonstrating different degrees of elasticity (3). Their formula to calculate the strain ratio was "strain of the reference area/strain of the lesion," which was identical to that used in Yun's research (1). The study (3) revealed that the strain ratio was proportional to the kPa value. However, according to Yun et al. (1), despite the fact that the $\mathrm{kPa}$ values increased in rotator cuff tendons with ACS, the corresponding strain ratios decreased inversely.

Additionally, the use of strain ratio lessens the influence of different compression forces exerted by the operators and is better than tissue strain to compare the elasticity among different objects (4). However, the investigators need to be aware whether the strain ratio has been derived from strain of the reference area divided by strain of the lesion/target or vice versa. Since the observation from strain ratio was possibly inconsistent with that derived from shear wave elastography in the present study, we would be grateful for the author's kind assistance in resolving our query.

\section{REFERENCES}

1. Yun SJ, Jin W, Cho NS, Ryu KN, Yoon YC, Cha JG, et al. Shearwave and strain ultrasound elastography of the supraspinatus 
and infraspinatus tendons in patients with idiopathic adhesive capsulitis of the shoulder: a prospective case-control study. Korean J Radiol 2019;20:1176-1185

2. Dietrich CF, Barr RG, Farrokh A, Dighe M, Hocke M, Jenssen C, et al. Strain elastography-How to do it? Ultrasound Int Open 2017;3:E137-E149

3. Havre RF, Waage JER, Mulabecirovic A, Gilja OH, Nesje LB.
Strain ratio as a quantification tool in strain imaging. Appl Sci 2018;8:1273

4. Lin CP, Chen IJ, Chang KV, Wu WT, Özçakar L. Utility of ultrasound elastography in evaluation of carpal tunnel syndrome: a systematic review and meta-analysis. Ultrasound Med Biol 2019;45:2855-2865 